\title{
Practice Needs to Be Braver: The Role of Entry to Care Panels
}

\author{
Tony Stanley ${ }^{*}$, Helen Lincoln ${ }^{2}$, Paul McGee ${ }^{1}$ \\ ${ }^{1}$ London Borough of Tower Hamlets, London, UK \\ ${ }^{2}$ Essex County Council, Essex, UK \\ Email: ${ }^{*}$ Tony.stanley@towerhamlets.gov.uk
}

Received 4 January 2014; revised 16 February 2014; accepted 9 March 2014

Copyright @ 2014 by authors and Scientific Research Publishing Inc.

This work is licensed under the Creative Commons Attribution International License (CC BY). http://creativecommons.org/licenses/by/4.0/

(c) (i) Open Access

\section{Abstract}

The English child protection system is a professionally orientated one. It is a system in which notions of risk and need are determined by professional child protection workers and managers, with significant decisions made about children known to be at risk. This includes decisions about fostering or alternative care. Yet, families tend to be left out of the various forums and debates where risk determinations and practice decisions actually happen. In this article, we examine how we have tried to address this imbalance by introducing an entry to care panel system. The panel can offer a helpful pause to rushed and pressured decisions to use care as an alternative to working with situations of risk. Child protection workers and their managers are invited to take a discursive look at how risk operates in each case. This has resulted in better child protection practice. We show how the type of panel we introduced played a significant part in evening out of the care numbers in two English local authorities. Our argument is for the panel to be seen as a practice initiative-An example of purposeful bureaucracy, where decisions reached or ratified are informed by risk and need discourses. We argue that this practice initiative has helped our workers to adopt a more critical approach to risk discourses in their child protection work. Practice based tools were introduced alongside of the panel to support this way of working. We show the gains for our practice, and importantly for the families we work with, as we work differently and more expansively with risk discourses.

\section{Keywords}

Risk; Entry to Care Panels; Child and Family Balance; Purposeful Bureaucracy

\footnotetext{
"Corresponding author.
} 


\section{Introduction}

The relationship between child protection and risk is a complex one. The rhetoric of risk on the one hand is used to identify those who meet the criteria for statutory child protective services, while at the same time legitimizing interventions for some and not for others. In England, for the most part, this remains the work of child protection social workers and their managers. It may seem surprising then that England lacks any uniformed approach to risk assessment or risk analysis in the child protection system (Cleaver et al., 2008; risk factors see Davies \& Ward, 2012). Instead, child protection social workers employ a range of tools to assist them "encode the imprecision of risk" including drawing on their own practice iterations and habits, their "simplifying rules of thumb" (Heyman, 2010), and in this article we explore how failure to recognize the limits of risk assessments can encourage a rather narrow practice focus.

Two problems arise when this narrow focus operates. First, the work of risk assessment and risk analysis tends to be regarded as a task for professionals, with families frequently being subjects of the decisions made. These decisions can include alternatives to family care or foster care. Second, some professionals outside of the child welfare system play a significant part in maintaining pressure on child protection workers to use care as a method of risk resolution. Some child protection workers will accept this and argue that a child being removed is a good way to manage risk. Other workers, as we show in this paper, are not so convinced that care provides such a risk free experience for young people. We report on how we responded to loud messages by some of our child protection workers that our risk work was too narrow and deficit focused, and we show the positive outcomes this has had for our clients and staff.

We argue that if we are to offer a better child welfare service to children and families, we need to recognize how power operates through the discursive language of risk and need and how this can easily be employed at the level of individual practitioner. We report on our progress in widening risk discourses in our practice by introducing an entry to care panel system. The panel's underpinning philosophy and architecture is engaged with in this paper. In Tower Hamlets, a sharp spike in the number of Bangladeshi teenagers entering care in 2007 prompted us to look at how a panel might help our practice when care was being promoted as the solution. Entry to care panels are common to most English local authorities, and we argue that the panel needs to be more than a gate keeping forum for resource decisions like fostering and residential care. Rather, we argue it can be a dynamic form of social work intervention. The aim here is for a reflective space where risk discourses can be actively drawn on to show how practice conversations about harm, danger, the future possibilities, hopes, uncertainties, and aspirations, can happen with families, and something not just professionally determined in deficit terms and then delivered to them. Narrow practice tends to un-invite family participation. Further, it discourages innovations like proportionate risk taking. We wanted to develop a braver practice in our organizations, and the entry to care panel helped us to achieve this.

Following a brief introduction to child protection in England, we argue that risk discourses have powerfully and rather uncritically shaped our contemporary practice. A rather narrow view of risk has emerged (Lonne et al., 2009; Oak, 2009), and we argue that this is likely to encourage what Connolly and Ward (2008) termed "professionally driven practice" rather than "risk work" being seen as something that can involve families. In our local authorities, care panel arrangements were established as a response to narrow definitions of risk driving decisions to place children and young people in formal care. In this paper, we draw on our direct practice experience as senior managers from two authorities-a unitary inner city authority and a large county council. We demonstrate how we have moved beyond a narrow and negative "risk society" paradigm after listening to a group of workers challenge simple and narrow notions of risk.

\section{Child Protection in England}

In England, Local Authorities are publicly funded to deliver statutory child protection. Child protection is grappling with necessary reform because decades of policy and procedural change have created an overly bureaucratized system where unrealistic expectations of risk resolution place child protection workers in an impossible position (Lonne et al., 2009; Munro, 2011). National prescription and central government edict organised the local delivery of child protective services for two decades. In fact, national prescription has contributed to the problem of risk assessment being regarded as a professional task, where risk is assessed, defined and delivered to families (Oak, 2009; see Davies and Ward 2012 for a discussion on risk factor analysis as a tool for professionals). Significant decisions follow that can include alternate care for some children. 
While the probability of non-accidental death in the UK is low, there is a wider societal perception that it is high and child protection child protection workers have the responsibility of identifying and preventing it (Kearney, 2013). The tragic and well documented death in London of 17-month-old Baby Peter Connelly in August 2007 led to rising demands in the UK for child welfare services because of the very public and political outcry to this and other child abuse tragedies. To some extent it is understandable that risk has taken such a discursive grip in the work of child protection. At a time of increasing scrutiny to the practices of statutory child protection this grip needs to be understood because the pressure on UK child protection workers to "get it right" has never been so great (Munro, 2011).

At the time of writing, the tragic death of four year old Daniel Pelka and the published serious case review dominates our media headlines. The serious case review was published in September 2013 and like many before it highlights the failure of agencies to communicate effectively. The death of any child is tragic, but so much more so when at the hands of an adult. When child welfare officers were directly involved with a family they became inextricably linked to the tragedy in the public eye. Practice is influenced, and tends to shift toward a more conservative direction, with more bureaucracy and regulation introduced, and so the cycle goes on. Thinking about risk in rather rigid, negative and fixed terms has emerged.

The Munro review of child protection (2011) attempted to address the English risk averse and overly bureaucratized practice cultures, and applied a systems thinking approach to child welfare organizations. Munro endorsed the need to maintain and develop effective and local child protection practice initiatives rather than being bound by rigid national statutory prescription and guidance. She argued that child protection workers are encouraged to "do things right", when this may not be the right thing for some children. Further, Professor Munro argued that innovation and risk taking in practice was unlikely in a system where audit and procedural dominance operated.

The English media is hostile and negative about child protective services in times of tragedy (Peckover et al., 2011). According to Gillingham (2006) risk discourses are partly to blame because of a widely held assumption that accurate risk prediction is possible. This is a practice lore widely held across child protection and mental health practice (Warner \& Gabe, 2004). It is indisputable that increasing rules, procedures and bureaucracy, however well intentioned, have followed tragedies in practice (Stanley, McGee, \& Lincoln, 2012). The nationally prescribed Integrated Childrens System (ICS) best illustrates this. It was introduced in the early 2000's to bring order and consistency to English child protective services (Wastell \& White, 2010). We think that electronic systems of case recording are important, and ICS has been credited for bringing an ordered approach to this (Liddicott, 2010), however, it never achieved one of its original intentions of telling "the child's story" in a coherent and accessible format. What occurred, however, was a hardening of rules and procedures, and for front line staff more time spent on computers completing paperwork and forms. This form filling culture has influenced child protection workers' thinking about risk because it has dominated their time with families around gathering the information necessary to inform the data set rather than explore the family's perception of risk, harm, need, danger and safety. This is combined with the practice habits of child protection workers being focused on the perceived safest options for children.

The problem for English child protection practice is a failure to recognize the limits of risk assessments as they encourage a narrow focus about risk options. Child rescue ideology subtlety operates, and any shift toward "child and family balanced" child protection is still in its infancy. Partly this is explained by a neo-liberal political and economic backdrop that continues to position the child as "a unit" in need of "statutory rescue" over other forms of family based intervention. Further, risk discourses tend to be understood in line with Beck's (1999) influential work as "being all pervasive" and this tends to play out in practice through risk aversion.

We introduce our local authorities next. This is followed by an explanation of the risk problem in more detail.

\section{Child Protection in Tower Hamlets}

Until recently, the authors worked together as part of the senior management team at Tower Hamlets Children's Social Care; an inner city urban London authority which has around 250,000 residents. The issues for the children and their families in Tower Hamlets include economic and social deprivation, access to resources, an everincreasing demand on shrinking resources, and the resultant lack of life opportunities. The wealthy banking and finance area of Canary Wharf is a stark backdrop to some very deprived communities. A diverse ethnic and migrant population adds to a rich cultural context of family life here, with $43 \%$ of residents born outside of the UK, and $32 \%$ of all residents being Bangladeshi identified and maintaining ethnic and cultural ties to the East Lon- 
don Bangladeshi community (Census, 2011).

Following well publicized child protection tragedies in England, increased demand was placed on child protective services, and, not surprisingly a rising number of children entered our care system year on year. In 2007 and 2008, a group of Bangladeshi and Asian child protection workers began to recognize the pitfalls of out of home care for the growing number of Bangladeshi girls entering voluntary care arrangements in Tower Hamlets. This was a rising population for our care system, and these workers observed that for many young women who entered care there was increased and as yet unthought-of risks for them. This prompted the introduction of the entry to care panel in 2009.

\section{Child Protection in Essex}

Whilst the communities it serves are somewhat different to Tower Hamlets, Essex County Council faced similar challenges with a spike in the number of children and young people being in taken into care. Essex is one of the largest local authorities in the UK geographically. It has 298,460 children and young people below the age of 18 . This is $21.1 \%$ of the total county population of 1.41 million (Census, 2011). The proportion of children entitled to free school meals is $11.3 \%$, which is below the national average of $16.6 \%$. Children and young people from minority ethnic groups account for $12.8 \%$ of pupils in primary schools and $11.0 \%$ of pupils in secondary schools. This is below the national average, and includes $0.2 \%$ children and young people from Traveller communities.

Essex children's services were placed on an improvement notice from central government in March 2009, following an external inspection by the national regulator which found child protection practice to be poor and service responses to children and their families inadequate. The authority at that time galvanized its energy and effort around the specifics of the targets and tasks placed upon it in the statutory improvement notice. The resultant picture was a piece meal completion of issues with the unintended consequence of risk-averse practice being promoted and reinforced. A significant and steady rise in the numbers of children entering care continued. By 2011, and in line with the Munro review recommendations, there was an organizational recognition that the approach to changing the service by being task focused was not working and a more systemic approach was needed.

\section{The Risk Problem for English Child Protection}

Complicating practice in England has been a lack of distinction between assessing risk and need using the Department of Health's nationally prescribed national assessment framework to assess children in need (Stafford et al., 2012). Moreover, the determining of a "child in need" pursuant to the 1989 Childrens' Act or a child in need of a child protection assessment reinforces a simple binary of need or risk. There was little if any invitation to consider risk discourses in practice as something more fluid and shifting, or how these in turn shaped practice. A risk averse practice emerged where the avoidance of errors dominates, heavily influenced by the well-publicized and tragic child deaths where statutory social workers had direct involvement (Butler, 2011). The pressure to defend decision making provided the basis of the blame culture that followed. As Douglas and Wildavsky (1982: p. 35) have argued blameworthiness takes over at the point where the line of normality is drawn. Each culture rests upon its own idea of what ought to be normal or natural. If a death is held to be normal, no-one is blamed. Child protection in England is likely to remain a very heavily scrutinized profession, high on public and media criticism when children tragically die at the hands of parents or caregivers. The pressure to get it right dominates practice. Avoiding tragedy then can help explain why risk becomes a useful discourse for child protection workers to determine up front, and then set out to resolve (Stanley, 2013).

Several commentators have noted how risk has narrowed in English social work, influenced in terms of the everyday understanding of risk being a bad or negative outcome. Peckover et al. (2011) found child protection workers used a range of informal work based practices and everyday understandings of risk to determine "at risk" categories for children that were applied to them. Heyman (2010) has drawn attention to the ways in which health risks are determined in professional spaces with risk categorization affected by the institutional setting of thresholds. Risk tends to be regarded as something objective and measurable, and this thinking has influenced ideas in child protection about how risk can be located, identified, and managed (Yearley, 2005; Webb, 2006).

The public and political condemnation of child protection in times of tragedy has led to what some have termed a precautionary and defensive approach to risk. A precautionary approach to risk management disregards the probabilities of events and "casts the future principally in negative, potentially catastrophic terms" (Alas- 
zewski \& Burgess, 2007: p. 349). Thus, child protection workers are reminded and encouraged to act cautiously. We argue this can be challenged to bring about a braver practice where risk taking with families can happen. However, we are acutely aware that the individual social worker will experience anxiety and worry that things may not go well.

While the classification of risk tends to be the work of child protection workers, and this very much shapes practice, this has been challenged by family-focused commentators (Keddell, 2011; Stanley, 2013; Turnell \& Edwards, 1999), who argue that families should help determine the risks that face their children. Stanley (2013) argued that family definitions of risk were not routinely asked for by child protection workers who participated in his research. Rather, workers sought confirmation of their risk judgments from other professionals involved, and this contributed to "high risk" classifications being made by child protection workers. According to Van Loon (2002), the process of accepting "everyday" understandings of risk conceals its socially negotiated construction. The risk society paradigm has significantly influenced how child protection workers construct risk. Beck (1992) and Gidden's (1994) argue that risk traverses social, physical and temporal boundaries: we are all potentially exposed to risk. However the challenge for practice, as Peckover et al. (2011) found, is that rather unsophisticated and narrow understandings of risk tend to operate in child protection practice. We argue that this narrowness limits family participation in decision making.

In the next section, we show how entry to care panels, led by senior managers, offer one way to interrogate, supportively, how risk is being drawn on and used in practice. We then show the gains for our practice and the better outcomes for our children and families.

\section{Entry to Care Panels}

While every local authority has some form of care entry or resource allocation panel, we found very little debate about these in the literature. Bunyan and Sinclair (1987) argued that gate keeping panels for care entry sprang up as a response to the rising numbers of children entering the care system in the 1980's. In the mid 1980's Leicestershire council established a care entry panel and parents were invited to attend if they wanted to voluntarily place children into statutory care (Bunyan \& Sinclair, 1987). Facing challenges of teenagers wanting to be in care and pressure to have them there, Bunyan and Sinclair (1987) argued that their care entry panel successfully kept one third of teenagers out of statutory care and with their families. Held (2005) advocated for care panels to reinforce a "higher tariff" entry point to care, and in so doing risk was a useful organizationally defined threshold. Others have been more critical of care entry panels because of the likelihood of promoting reduced professional confidence by child protection workers around decision making (Kendrick \& Mapstone, 1989).

\section{How We Researched the Entry to Care Panel}

This paper is based on our direct experiences as a group of senior colleagues interested in how some of our workers challenged the way narrow risk definitions shaped their practice (Stanford, 2010). We were interested in how the organizational change of introducing a panel made a difference in risk work. We have taken a case study approach (Yin, 2008) toward the two entry to care panels discussed—one set up in Tower Hamlets in 2009, and the other more recently in Essex. We have been influenced by Smith's (2005) ideas about institutional ethnography and have followed her approach: Institutional ethnography begins in the local actualities of the everyday world, with the concerns and perspectives of people located distinctively in the institutional processes (Smith, 2005: p. 34). We understand ethnography as a "concern with the meaning of actions and events to the people we seek to understand" (Spradley, 1980: p. 5). Mostly, this has involved McGee directly observing child protection workers as they presented their cases to panel, the practice talk this generated and the panel decisions and Stanley attending in his role as a social worker. McGee has been a panel member since 2009 and participated in over 100 panels. Key policy documents that were associated with the set up and initial evaluation of the panel were also reviewed. Taking a purposeful approach to data collection, we limited this to the existing documents we could access, McGee's direct observations and experiences with the panel, and discussions with three insiders, that included a senior Bangladeshi colleague. Boyd's (2010) evaluation project of the first six months of the panel was helpful and provided useful evidence and insights into how the panel was functioning and influencing practice.

The main focus for this research was to consider the relationship between the panel and child protection workers' talk about risk. We acknowledge our insider status. Stanley has attended the panel in his role as prin- 
cipal social worker on ten separate occasions, and attended several more to observe. McGee has sat on over 100 panels, and this along with Lincoln's senior oversight of the panel decisions provided the empirical data for this paper. We followed Liamputtong \& Ezzy's (2005) version of thematic analysis. The research project unfolded from mid-2012 and into 2013. The monthly management information reports were analyzed for the numbers of care entry and exits in Tower Hamlets and Essex and ethnicity was considered. The authors met regularly as this project unfolded, for reflexive discussions about what we were finding and what we thought it meant.

The three authors hold senior positions within their respective organizations, and recognized the inherent power differential this means for research with child protection workers and lower tier managers. While the initial evaluation data was available (Boyd, 2010), and our reflexive work as part of the panel is our lived experience, we interviewed three other senior colleagues about their experiences as panel members on panel, and as managers going to panel with their workers. The authors are all registered social workers and experienced researchers. Our conclusions are limited because we did not ask social workers about their experiences of the panel, recognizing the explicit power differentials here; however their anonymous feedback as part of the annual social work health check gave us some insight into how they saw the panel assisting them and indeed how it did not.

\section{Antecedents for the Tower Hamlets' Entry to Care Panel}

Between 2006 and 2007 a spike in the number of children entering care in Tower Hamlets occurred. This was significant for teenagers, with 70.5\% aged between 10 and 17 . This was up from 59\% in 2006. This included a significant increase in one cohort of Bangladeshi teenage girls. The issues that precipitated the care decisions for this group included physical chastisement, parental discord, risk taking behaviors, and pressure from external agencies to place the teenage girls into care. Pressure came from police, schools, parents and the young people themselves. The majority of these girls were challenging their parents' authority in ways that were new to the parents. Drinking alcohol, staying out all night with friends, seeing boys and not going to school challenged the parents. It is important to note that the parents did not see their responses to be abusive. The girls ages ranged from 14 - 16 and there had not been any previous child protection involvement with their families. The girls were supported by a group of teachers, who strongly advocated that they were at "risk of harm" and needed to be removed from their parents. This presentation of high risk by parents, teachers and police was in rather narrow terms, yet compelling. Social workers were pressured by the young Bangladeshi women themselves, and some made allegations of physical abuse against their parents and then "demanded to be removed" from home, stating that they did not feel safe. Child protection investigations ensued that highlighted a number of issues that contributed to a picture of "high risk".

A small and active group of Asian and Bangladeshi practitioners questioned this. They argued that risk is a complicated idea for each young person and their family and something not easily resolved by quick fix, and narrow "one size fits all" approaches like statutory care. In several instances risks for the young people increased while they were in care, and our working partnerships with some families deteriorated. This group of child protection workers did not condone the use of physical chastisement and parents were told that this was not an acceptable form of discipline. New assessments carried out by the child protection workers showed that the risks were not significant enough to justify the girls being in care. Parents were just struggling to cope with behaviors that challenged their cultural and religious norms. Pressure continued by external agencies. Some school staff complained that Bangladeshi child protection workers were colluding with parents and exposing the girls to harm at home. The language of "forced marriage" and "honor based killings" was uncritically drawn on by police and school staff, and this contributed to the classification of "at risk". This cohort of girls did enter care, albeit for a brief period. The majority of them drifted home.

To interrupt this practice, the senior management team piloted an entry to care panel. Made up by senior child protection managers, a senior education representative and a senior health representative, the panel commenced as a six month pilot in October 2009. Initially the panel focused on care decisions for children aged 11 and over as a direct response to the cohort of Bangladeshi teenagers who had entered care.

\section{How the Entry to Care Panel Works}

There are three phases to the panel process. The first is a preparation phase, where workers interrogate the risk and harm issues for each case with their manager. Because child protection workers know that panel will make 
recommendations for family based work, like convening a family group conference, to help resolve issues, we are seeing more family focused work happening earlier in the case. Cultural genograms are prepared prior to going to panel. This was one of the child protection tools introduced to support risk analysis work. The next phase is going to panel. The social worker is given license to engage openly with risk and at its most dynamic the panel is form of social work intervention in each case. Key components are presenting the child's narrative, a genogram and family eco-map supported by a succinct précis of the social work analysis to date, see (Stanley et al., 2012). The worker engages the panel, and the case is discussed in "risk terms". At the end of the panel debate, senior endorsement is provided for the decisions reached. Having tough conversations about young people not coming into care is one of the outcomes social workers say they feel more able to do.

An evaluation of the first six months highlighted the promise of the panel. As part of her higher degree, Boyd (2010) evaluated the first six months of the Tower Hamlets panel and concluded that of the 45 young people presented there was refusal to use care for 20. Of these, seven were returned later to panel and three subsequently entered care. The majority of children where care was refused remained at home indicating that decisions for refusal to care were appropriate. Boyd (2010) found that more focused and purposeful child protection practice was being done prior to presenting the case at panel. Risk was being engaged with differently and more expansively. Through focus groups with team managers, independent reviewing officers and panel members, she found wholehearted support for the panel in shifting the responsibility from child protection teams to make risk management decisions (that included care as one option) to a panel of senior colleagues where decisions for care were discussed and ratified. Child protection workers were initially apprehensive in this decision making shift, however they expressed relief at the endorsement of care plans and the sharing of risk decisions.

Boyd (2010) concluded that child protection workers undertook and attempted a wide range of family based interventions prior to going to panel, that included the use of family meetings to try and resolve problems. They were beginning to talk about their risk analysis work at panel. In cases where care was refused at panel, members offered a range of practice suggestions and explained how risk could be worked with in a "child and family" focussed way. Risk then became a helpful construct in case discussions to support workers thinking about a more family focussed practice. Taking risks in practice then became organisationally supported. Following the pilot and evaluation phase, the panel remit was extended to include all children and young people who were considered to be in need of statutory care. The panel introduced a process of gate-keeping by senior managers, taking responsibility from child protection workers and making them feel less vulnerable to the kinds of pressures from outside agencies. The Panel offered a place for talking about taking risks for example, having a teenager stay with relatives for a short while, knowing that they may leave or run away. This work has reoriented many practitioners toward a "child and family" balance in their practice. This is an important shift from one of "child rescue" where care may have been seen as a way to mitigate risk.

Despite the growing population of Bangladeshi children under the age of 18, with the changes in child protection practice outlined above we have not seen an increase in the 13 plus age group entering care, which we saw during the previous 5 to 6 -year period. There has been a reduction in the 13 - 17 age group from 60 entering care in 2009 to 43 entering care in 2012. The number of Bangladeshi adolescents entering care has reduced overall. Against a growing Bangladeshi population in the borough this illustrates a significant development in our strategies for intervening with this community.

\section{Essex County Council Care and Resource Panels}

The learning from Tower Hamlets was transferred to Essex when Lincoln became their Director of Childrens Services. A complete reshaping of the approach to children's child protection was embarked on when she arrived. The county was restructured from a centralised model into four local divisions with each division having whole service responsibility. Each division set up a local panel, attended by local services managers. Child protection workers attend the panel and present their case about risk and their argument for care. Their team manager goes with them. Initially, the experience was similar to that of Tower Hamlets. Child protection workers said they were nervous and reserved about being asked to explore the case through a wider risk lens. The panel members asked for a more detailed and balanced risk analysis to be presented. Generalizations or overly simplistic case presentations emphasizing high risk were challenged. This encouraged child protection workers to do more preparatory work that involved family based interventions prior to coming to the panel.

Alongside the setting up of the care resource panels in Essex, there was recognition that the service mix was also driving risk aversion with little alternatives than care entry. Taking a more systemic focus the council then 
withdrew from being a provider of residential care services for young people and closed its eight "main stream" children's homes, and secondly set up intensive family intervention teams to trial what might work to divert young people from care. The rationale for establishing this service was in line with a long term view of changing the culture and approach of child protection practice with families who are struggling with parenting teenagers. Working from the basis that confidence and skill of the individual practitioner reduces risk aversive practice we challenged the case work habit that care is a "safest option" when managing the needs of young people who are presenting a range of challenging and risky behaviors.

The number of Essex children in care significantly rose between 2008 and 2011, while in the early 2000's there was on average 1300 children and young people in care. By May 2011 this had risen to 1580 children and young people in care at any one time. In 18 months since the care panels started the overall number of children in care has been reduced by more than 300 . The trajectory of care numbers continues to decline.

\section{Discussion}

In this article we have shown that child protection workers can be invited to think about and work with risk differently, and challenge the narrowness of risk in practice. We need our workers to understand the disconnect between risk as an event, or something that might occur later, and actual events of child injury or harm occurring in the present, and to use the panel as a resource to tease this risk thinking out. Zinn (2008) made the case for exploring the constructions of risk through discourses of trust and intuition, something child protection workers can do through a critical questioning approach at panel, in supervision, and importantly with families because they are encouraged to work with the risks in each case, and avoid swift decisions like care. Any need to render risk into more certain measurable and objective facts is problematic for child protection practice. The understandings of risk as an objective phenomenon is grounded in a search for confirmation evidence and as risk gets reified as an objective reality this makes it difficult for families and young people to challenge (see Heyman's discussion of risk classification in forensic mental health Heyman et al., 2013).

The overall impact of the panel has helped us achieve a cultural shift in our approach to child protection practice. What is now driving practice tends to be direct work and quality contact with families where risk and need are discussed in more open and collaborative ways. The introduction of the panels has helped to establish a routine dialogue about risk approaches to family issues and a more sensible approach to finding solutions outside of formal care arrangements. The pressure on Tower Hamlets child protection workers to place a cohort of Bangladeshi female teenagers in care illustrates why this is important. The risks identified by police and school staff were presented in "catastrophic terms" with coming into care as the inevitable solution and this was difficult to argue against prior to the entry to care panel. We have introduced a range of practice tools informed by the "signs of safety" approach to child protection to support risk analysis work (Stanley et al., 2012).

Child protection workers at panel are invited to confront risk "as risk" (Giddens, 1994), as this provides them a point of analysis about their child protection practice. Confronting risk in this way requires "forms of discussion that develops risk consciousness, management systems and public discourse in ways that re-skill professionals and lay people” (Ferguson, 1997: p. 232). Parton's (1998) argument, echoed by Bessant (2004), is that risk should not be seen as synonymous with uncertainty and something needing to be ordered. We argue that risk needs to be worked with, not simply mitigated against. However, the pressure for child protection workers to act in risk resolution terms can be subtle and enduring. While the number of Bangladeshi teenagers entering care in Tower Hamlets has continued to decrease, the 2009 episode of the Bengali cohort has shown us that totalizing risk discourses contributed to the pressure experienced by our staff from external agencies, family members and even the teenage girls themselves. We think that our workers are now more able to have sophisticated risk conversations with families, professional colleagues and young people because of their engagement with risk discourses at panel.

\section{Purposeful Bureaucracy}

Professionally led meetings and bureaucratic risk procedures have tended to position families as recipients of welfare and not as co-producers of knowledge about risk. Managerial imperatives contribute to this "closing out”. Lonne et al. (2009) have argued that managerial dominance is very much alive and well in UK child protection organizations. This needs addressing if risk management is to become more useful to informing and debating decisions, rather than risk being drawn on as a legitimate argument for uncritical protective action. As 
shown, child protection workers can be pressured to rush to replace the uncertainty and messiness of everyday family life in which some children might get hurt with the certainty of a world in which all children are safe (Mason, 1993), and care being seen as one way to achieve this. Not only is this unrealistic, the goal minimizes the possible harm for a child by placing them into care.

While the panel is in place for decision making for children to come into care, there is no equivalent panel that meets to review those still in care. This is something that the senior management team at Tower Hamlets is introducing to help guard against drifts in care. The idea is for child protection workers to visit the panel again and make the case as to why a child needs to remain in care. The involvement of families in our statutory practice is by no means new idea, however England's child protective services has some way to go to really provide participative families practice. We think that the entry to care panel's in Tower Hamlets and Essex are on the right track toward a better balance.

\section{Conclusion}

In Tower Hamlets, the driver for the entry to care panel was to enable a supported credible redress and balanced approach to decisions about care for Bangladeshi teenagers. In Essex, the driver was to get a systems wide grip on the cases and to guide and promote practice consistency. In both cases the panel has invited and encouraged a practice shift toward working more expansively with risk. We have moved our culture of child protection work from a narrow and deficit led approach to one where the "personal troubles" of children and families are understood within a wider "community of practice" context. It has taken a systems change approach to establish this new way of thinking in our organizations, and this has re-orientated our practitioners toward "a child and family balance".

\section{References}

Alaszewski, A., \& Burgess, A. (2007). Risk, Time and Reason. Health, Risk \& Society, 9, 349-358. http://dx.doi.org/10.1080/13698570701612295

Beck, U. (1999). World Risk Society. Cambridge: Polity Press.

Bessant, J. (2004). Risk Technologies and Youth Work Practice. Youth and Policy, 83, 60-77.

Boyd, J. (2010). Teenagers Entering Care in Tower Hamlets-Assessing the Effect of a New “Entry to Care Panel”. Thesis, Westminster, MA: Westminster University.

Bunyan, A., \& Sinclair, R. (1987). Gatekeepers to Care. Practice: Social Work in Action, 1, 116-128. http://dx.doi.org/10.1080/09503158708416835

Butler, P. (2011). Baby P Effect Puts Record Number of “at Risk” Children in Care. http://www.guardian.co.uk/society/2011/sep/08/baby-p-effect-child-protection

Cleaver, H., Wattam, C., \& Lawson, P. (1998). Assessing Risk in Child Protection. London: NSPCC.

Connolly, M., \& Ward, T. (2008). Morals, Rights and Practice in the Human Services. London: Jessica Kingslea Publishers.

Davies, C., \& Ward, H. (2012). Safeguarding Children: Message from Research. London: Jessica Kingslea Publishers.

Douglas, M., \& Wildavsky, A. B. (1982). Risk and Culture: An Essay on the Selection of Technical and Environmental Dangers. Berkeley, CA: University of California Press.

Ferguson, H. (1997). Protecting Children in New Times: Child Protection and the Risk Society. Child and Family Child protection, 2, 221-234.

Giddens, A. (1994). Living in a Post-Traditional Society. In U. Beck, A. Giddens, \& S. Lash (Eds.), Reflexive Modernization: Politics, Tradition and Aesthetics in the Modern Social Order (pp. 56-109). Cambridge, England: Polity.

Gillingham, P. (2006). Risk Assessment in Child Protection: Problem Rather than Solution? Australian Child Protection, 59, 86-98.

Held, J. (2005). Qualitative Study: The Placement Stability of Looked after Children. Report for Department for Education and Skills. London: DfES.

Heyman, B. (2010). The Social Construction of Health Risks. In B. Heyman, A. Alaszewski, M. Shaw, \& M. Titterton (Eds.), Risk, Safety and Clinical Practice: Health Care through the Lens of Risk (pp. 37-58). New York: Oxford University Press.

Heyman, B., Godin, P. M., Reynolds, L., \& Davies, J. P. (2013). Assessing the Probability of Patients’ Reoffending after Discharge from Low to Medium Secure Forensic Mental Health Services: An Inductive Prevention Paradox. Health, Risk \& Society, 15, 84-102. http://dx.doi.org/10.1080/13698575.2012.751090 
Kearney, J. (2013). Perceptions of Non-Accidental Child Deaths as Preventable Events: The Impact of Probability Heuristics and Biases on Child Protection Work. Health, Risk \& Society, 15, 51-66. http://dx.doi.org/10.1080/13698575.2012.749451

Keddell, E. (2011). Reasoning Processes in Child Protection Decision Making: Negotiating Moral Minefields and Risky Relationships. British Journal of Social Work, 41, 1251-1270.

Kendrick, A., \& Mapstone, E. (1989). The Functions Of Child Care Reviews In Scotland: A Preliminary Investigation. British Journal of Child protection, 19, 407-419.

Liamputtong, P., \& Ezzy, D. (2005). Qualitative Research Methods. Oxford: Oxford University Press.

Liddicott, S. (2010). ICS Panel Says Criticism of System Is Unfair. http://www.communitycare.co.uk/articles/19/02/2010/113849/ics-panel-says-criticism-of-system-is-unfair.htm

Lonne, B., Parton, N., Thomson, J., \& Harries, M. (2009). Reforming Child Protection. London: Routledge.

Mason, B. (1993). Towards Positions of Safe Uncertainty. Human Systems, 4, 189-200.

Munro, E. (2011). The Munro Review of Child Protection: Final Report: A Child-Centred System (173 p). London: Stationery Office. http://www.scie-socialcareonline.org.uk/profile.asp?guid=769910a9-fc20-4941-80b8-a5969a74ba8d

Oak, E. (2009). Social Work and Social Theory. Houndmills: Palgrave.

Parton, N. (1998). Risk, Advanced Liberalism and Child Welfare: The Need to Rediscover Uncertainty and Ambiguity. British Journal of Child protection, 28, 5-27.

Peckover, S., Wastell, D., White, S., Broadhurst, K., Hall, C., \& Pithouse, A. (2011). The Fallacy of Formalisation: Practice Makes Process in the Assessment of Risks to Children. In H. Kemshall, \& B. Wilkinson (Eds.), Good Practice in Assessing Risk: Current Knowledge, Issues and Approaches (pp. 84-101). London: Jessica Kingslea.

Smith, D. E. (2005). Institutional Ethnography: A Sociology of the People. London: Altamira Press.

Spradley, J. (1980). Participant Observation. New York: Holt, Rinehart and Winston.

Stafford, A., Parton, N., Vincent, S., \& Smith, C. (2012). Child Protection Systems in the United Kingdom: A Comparative Analysis. London: Jessica Kingsley.

Stanford, S. (2010). Speaking Back to Fear: Responding to the Moral Dilemmas of Risk in Child Protection Practice. British Journal of Child Protection, 40, 1065-1080.

Stanley, T. (2013). “Our Tariff Will Rise”: Risk Probabilities and Child Protection. Health Risk and Society, 15, 67-83. http://dx.doi.org/10.1080/13698575.2012.753416

Stanley, T., McGee, P., \& Lincoln, H. (2012). A Practice Framework for Assessments at Tower Hamlets Children’s Social Care: Building on the Munro Review. Practice, 24, 239-250. http://www.ingentaconnect.com/content/routledg/cpra;jsessionid=vxodcvwhqsma.alice

Turnell, A., \& Edwards, S. (1999). Signs of Safety: A Solution and Safety Oriented Approach to Child Protection Casework. New York: Norton.

Van Loon, J. (2002). Risk and Technological Culture: Towards a Sociology of Virulence. London: Routledge. http://dx.doi.org/10.4324/9780203466384

Warner, J., \& Gabe, J. (2004). Risk and Liminality in Mental Health Social Work. Health, Risk \& Society, 6, 387-399. http://dx.doi.org/10.1080/13698570412331323261

Wastell, D., \& White, S. (2010). Technology as Magic: Fetish and Folly in the IT-Enabled Reform of Children’s Services. In P. Ayre, \& M. Preston-Shoot (Eds.), Children Services at the Cross Road: A Critical Evaluation of Contemporary Policy for Practice (pp. 107-114). Plymouth: Russell House.

Webb, S. A. (2006). Child Protection in a Risk Society: Social and Political Perspectives. New York: Palgrave Macmillan.

Yearley, S. (2005). Making Sense of Science: Understanding the Social Study of Science. London: Sage.

Yin, R. (2008). Case Study Research: Design and Methods. London: Sage.

Zinn, J. (2008). Heading into the Unknown: Everyday Strategies for Managing Risk and Uncertainty. Health, Risk \& Society, 10, 439-450. http://dx.doi.org/10.1080/13698570802380891 